\title{
ISPC 2007 second editorial
}

\author{
Tami I. Spector
}

Published online: 10 February 2009

(C) Springer Science+Business Media B.V. 2009

I am pleased to present the second set of papers from the ISPC symposium held at the University of San Francisco in August 2007. The third and final set will be published in another issue of Foundations later this year. The papers contained in this issue cover a greater variety of topics related to the philosophy and history of chemistry than those from the symposium published in Foundations of Chemistry 10.3. These disparate topics have the advantage of revealing how diverse the field of philosophy of chemistry has become. Thus, N. Sukumar's "The Chemist's Conception of Molecular Structure" and James Salmon's paper on emergence tread different paths, but both provide new perspectives on topics that have received relatively cursory attention from scholars within the field; by contrast, Pio Garcia, Richard Pagni, and Meredith Tromble's papers on serendipity, the history of the acidity function, and Sonia Rapaport's art, respectively, provide virtually new pathways for philosophers of chemistry to investigate.

N. Sukumar's "The Chemist's Conception of Molecular Structure" provides a chemist's-eye view on the current debate on structure in philosophy of chemistry. Rather than arguing for or against the realism of molecular structures and representations he provides a thorough review of ways physical chemists have theorized molecular structure. Starting with the Born-Oppenheimer Approximation (BOA) he shows us the limits of the BOA approach, its modification via virial partitioning into the Quantum Theory of Atoms in Molecules, and how chemists have moved beyond the BOA altogether to formulate new theories, like Nuclear Orbital plus Molecular Orbital theory, that include, among other things, the dynamic aspects of molecular structure such as Jahn-Teller Molecules, tautomers and the conformational flexibility of biomolecules.

James Salmon's "Emergence in Evolution" argues that explanations for emergence in evolution, including the evolution of life forms, cosmic evolution and the evolution of chemical/biochemical systems, goes beyond that captured by the quantitative notion of "frequency of occurrences". As an alternative to Whitehead's process metaphysics, which others have applied to emergence in chemical systems, Salmon suggests Teilhard de Chardin's informal metaphysics of spirit-matter as an equally valid, and more accessible,

T. I. Spector $(\square)$

University of San Francisco, San Francisco, CA, USA

e-mail: spector@usfca.edu 
philosophical framework for emergence in science. As he proposes, when we incorporate "ontological monism", "novel causal influences", "downward causation", and the unpredictability at bifurcation points for chemical systems, we meet the qualitative conditions for the scientific validation of emergence. Using this quartet of conditions he demonstrates, in turn, how the periodic table and oscillating clock reactions (i.e., selforganizing chemical processes) fulfill the criteria of philosophical emergence.

In "Discovering by Serendipity: a New Concept for an Old Riddle", Pio Garcia untangles the underlying philosophical assumptions associated with the ways scientists, and more specifically combinatorial chemists, use the term serendipity. Citing historically important cases of "accidental" discovery in the sciences, in parallel with an explication of problem-solving metaphors, he philosophically parses serendipity's meaning into four "aspects": (1) accidental circumstances, (2) a kind of search, (3) a prepared mind and (4) finding a thing that is not being sought. Although the meaning of serendipity originates in aspect 4 , he demonstrates that the other three, in various combinations, also have historically relevant explanatory power. Once Garcia elucidates the term serendipity, he delves deeper to reveal the implications of the term "serendipity mistake" commonly employed by scientists when derogatorily referring to the unrestricted blind search "first approach" used by first-generation combinatorial chemists. He concludes that despite the negative rhetorical interpretations attached to the terminology, the "first approach" was a rational and creative scientific strategy.

Richard Pagni's "The Origin and Development of the Acidity Function" provides a historical account of Hammett's ground-breaking extension of acid/base theory to include concentrated acids under non-ideal conditions. As Pagni reveals, illuminating in the process our understanding of the history of acids in chemistry, Hammett's theory not only quantified their non-ideal behavior but also provided an important means for mechanistic evaluation that is still used today. For example, in a recent Journal of Organic Chemistry paper, Shukla and DeShong use Hammett's methods to study the mechanism of "palladium-catalyzed allyl-aryl coupling reactions" (Shukla and DeShong 2008). Pagni situates Hammett's work within the context of other renowned chemists working on acids during his era, such as Bronsted, Conant and Hall along with those who picked up the acidity function mantle after Hammett. One such chemist was George Olah, who pushed the quantification of acids into the realm of "super acids" by combining Bronsted and Lewis acids in the 1980s.

Finally, Meredith Tromble, as the title "The Advent of Alchemical and Chemical Symbolism in the Art of Sonya Rapoport" suggests, focuses on this pioneering New-Media artist. The works discussed in this paper focus, in the main, on two specific pieces that Rapoport began in the late 1970s using the chemical symbology she accumulated, in part, due to her proximity to her late husband, the chemist Henry Rapoport; these are the Objects on My Dresser: Displacing Elements on the Periodic Table and the Cobalt series. Through thick description of these artworks (and with reference to others), recollections from Rapoport, and supple artifactual analysis, Tromble reveals how Rapoport juxtaposed molecular structures, atomic and alchemical symbols against representations of non-scientific objects to create socially and personally encoded interactive spaces that link the viewer to the metaphysics of alchemical and chemical transformation.

Despite the diversity of content in this issue, the authors open up a stimulating intellectual space, one that permits magnetic relationships to flow among the ideas running through these articles. Among the accidents that brought these papers together are the imaginative approaches the authors bring to the Philosophy of Chemistry. These papers thus allows us to ponder relationships that may inhere between new ways of conceiving 
chemical structure, a chemical basis on which emergence in evolution can be built, the philosophical validity of serendipity, the reexamination of a chemist in the history of acid/ base theory, and the synergy of visual art and physical science.

\section{Reference}

Shukla, K.H., DeShong, P.J.: Studies on the mechanism of allylic coupling reactions: a Hammett analysis of the coupling of aryl sillicate derivatives. Org. Chem. 73, 6283-6291 (2008) 